\title{
Correction to: The occurrence of seizures after ischemic stroke does not influence long-term mortality; a 26-year follow-up study
}

\author{
J. H. van Tuijl $1^{1,2}$ - E. P. M. van Raak ${ }^{1}$ R. J. van Oostenbrugge ${ }^{1,3,4} \cdot$ A. P. Aldenkamp ${ }^{1,3,5,6} \cdot$ R. P. W. Rouhl $1^{1,3,5}$
}

Published online: 31 August 2018

(c) The Author(s) 2018

\section{Correction to: Journal of Neurology (2018) 265:1780-1788 https://doi.org/10.1007/s00415-018-8907-7}

The original version of this article unfortunately contained a mistake. The copyright line was incorrect in the HTML version. The correct copyright line should be "The Author(s) $2018 "$.
Open Access This article is distributed under the terms of the Creative Commons Attribution 4.0 International License (http://creativeco mmons.org/licenses/by/4.0/), which permits unrestricted use, distribution, and reproduction in any medium, provided you give appropriate credit to the original author(s) and the source, provide a link to the Creative Commons license, and indicate if changes were made.
The original article can be found online at https://doi.org/10.1007/ s00415-018-8907-7.

\section{R. P. W. Rouhl}

R.Rouhl@mumc.nl

1 Department of Neurology, Maastricht University Medical Center, PO Box 5800, 6202 AZ Maastricht, The Netherlands

2 Department of Neurology, Elisabeth-Tweesteden Hospital, Tilburg, The Netherlands

3 School for Mental Health and Neurosciences, Maastricht University, Maastricht, The Netherlands

4 Cardiovascular Research Institute Maastricht (CARIM), Maastricht University Medical Center, Maastricht, The Netherlands

5 Academic Center for Epileptology, Maastricht University Medical Center and Kempenhaeghe Center of Expertise for Epileptology, Maastricht, The Netherlands

6 Faculty of Electrical Engineering, University of Technology, Eindhoven, The Netherlands 